\title{
Evaluating the Quality of Rewards Systems ${ }^{\#}$
}

\author{
Petr PETERA*
}

\section{Introduction}

Performance measurement and management systems (hereinafter "PMMS") and rewards systems (hereinafter "RS") are generally considered to be an important factor of a potential competitive advantage and thus are still on the agenda. The structure and content of the paper are conforming to its purpose, which is twofold. Firstly, we want to give an overview of relevant literature, explain the approaches that we consider to be the most progressive and outline our views on rewarding. Secondly, we want to develop a framework for assessing properties and quality of RS. This framework will be (with some restrictions) used for the first phase of our empirical research and after some adjustments it should be usable by companies as a tool for self-assessment and identification of the key problems of their RS.

Therefore this paper will be used as a theoretical basis for formulating research questions about the fundamental properties of RS like:

- Are desirable characteristics and requirements met by an implemented RS?

- Which types of rewards and how extensively are used?

- Which tools are used for motivating the workforce?

- Are incentives (especially variable pay) used and if so, how are they implemented?

\footnotetext{
\# The article is processed as an output of a research project Systém měrení a ř́zení výkonnosti podniku a jeho vazba na systém odméňování a motivace pracovníků (Performance measurement and management system and its connection with the system of rewarding and motivating workforce) registered by the Internal Grant Agency of the University of Economics, Prague under the registration number F1/9/2011.

Ing. Petr Petera - chief of controlling; Teplická strojírna s. r. o., Hřbitovní 723, 41503 Teplice 3, Czech Republic; <petrpetera@ volny.cz>.
} 


\section{Rewards system and its position within a broader context}

\section{Aims, functions and desirable characteristics of rewards system}

The aims and priorities of RS depend on the situation in which a company operates and so it is not possible to give universal advices. Well, it is possible to identify common aims that are usually in place supporting business's goals, attracting, motivating and retaining competent employees (WorldatWork, 2007, p. 90). In order to be able to fulfil these aims, RS has to prove certain properties and we accept the following simple framework as a basis for our considerations. Quality of $\mathrm{RS}$ is determined by rewards strategy, current properties of implemented RS and deployed procedures for updating RS.

Fig. 1: Framework for analysing rewards system

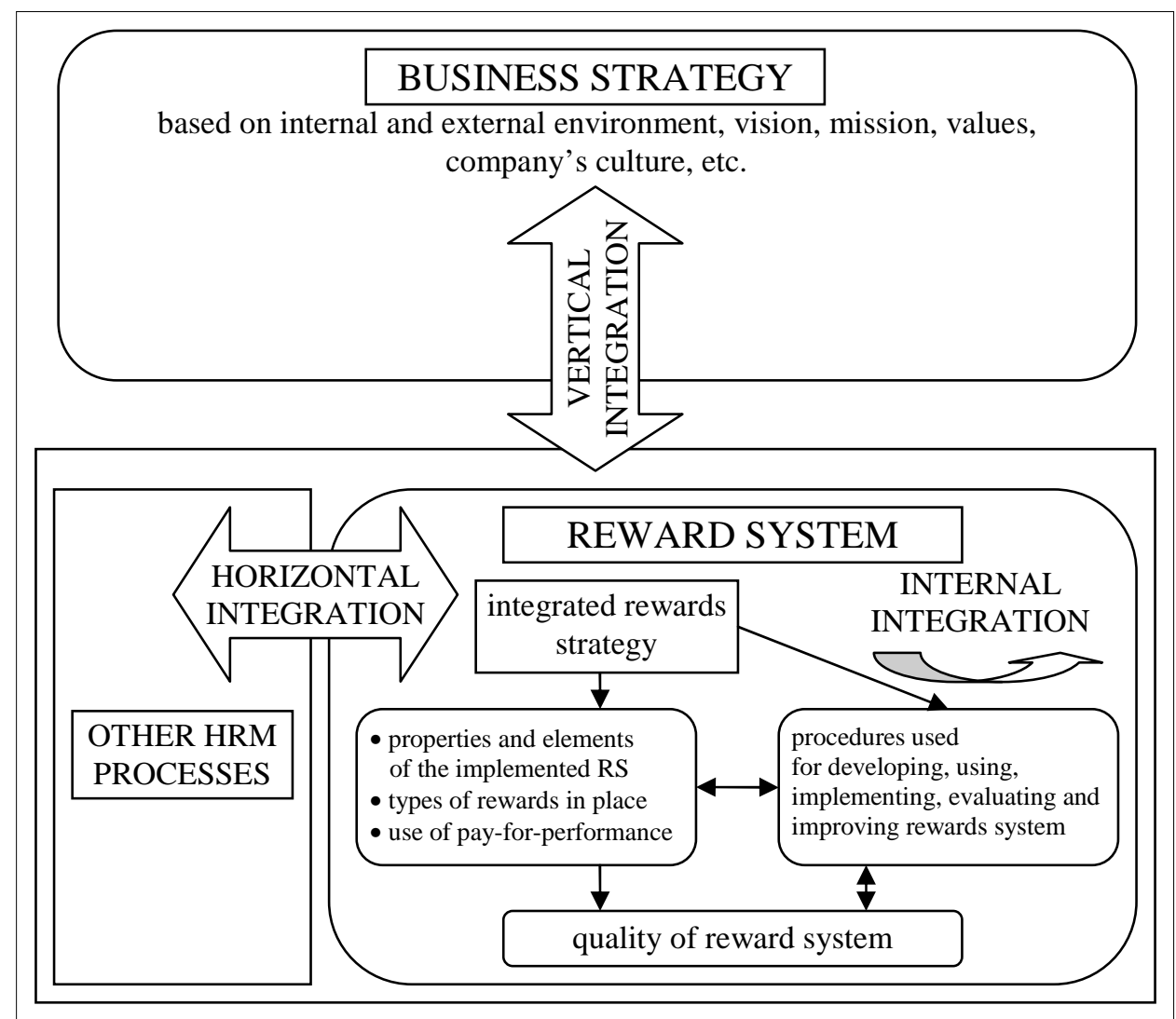

Source: own scheme based on (Armstrong, 2010), (Armstrong - Brown, 2010),

(WorldatWork, 2007) 
Petera, P.: Evaluating the Quality of Rewards Systems.

\section{Rewards strategy}

Rewards strategy incorporates decisions that should be applied consistently in a long-term period (Armstrong, 2010, p. 28). Fig. 1 shows that RS should be internally, horizontally and vertically integrated. Internal integration means that components of RS should form a coherent whole and appropriate types of rewards should be used for the appropriate purposes. Horizontal integration means that RS should be aligned with other human resources management activities (see chapter "Alternative ways of influencing employee's behaviour"). Vertical integration means alignment with a company's strategy, mission and values. Integration is emphasized for example by Armstrong (2010, p. 7-8).

Rewards strategy should according to (WorldatWork, 2007, p. 24-25) and (Armstrong, 2010, p. 30) include:

- goals of RS, their prioritization and success criteria,

- statement about how RS will support business strategy and needs of the company's stakeholders,

- list of rewards types including their description and relative importance,

- setting the importance of rewards relative to other tools of influencing employees behaviours,

- identification of procedures for updating RS,

- selection of measures which should be used for determining rewards including decision on what level will be measurement realized (organization-wide, SBU, team, individual) and decision which elements of total rewards will be linked to those measures,

- selection of competitive market reference points (that is subjects that will be used for determining the competitiveness of the rewards package),

- decision on desired competitive position to the selected reference points (e.g. company's level of rewards may be below, equal or above market),

- guidelines for solving conflicts (e.g. between internal equity and external competitiveness),

- decision about how intensive will be communication about rewards with stakeholders and which information about rewards will be disclosed,

- data and information management-selecting of information sources, methods of data processing and reporting for decision support. 


\section{Commonly desired properties of RS}

After reviewing literature we concluded that the most comprehensive framework for evaluating of RS is (as far as we know) given in (Armstrong - Brown, 2010, p. 112). According this framework, rewards system effectiveness is given by a degree to which the system is:

- competitive,

- convergent,

- rewarding contribution and performance,

- customized,

- committing employees,

- communicated,

- cost effective,

- easy to change,

- controlled,

- compliant.

Despite the comprehensive nature this framework it is important to emphasize that:

- The framework is a bit mixed up as it includes both requirements on properties of RS and requirements on procedures that should be put in place. Some of the requirements are also overlapping with the requirements on vertical, horizontal and internal integration of RS.

- Mentioned properties are just guidelines, not always all can be met to the full extent (e.g. because being in a mutual conflict - e.g. internal equity and external competitiveness (WorldatWork, 2007, p. 90)).

- It does not explicitly highlights that RS should be based on the selected reward strategy and does not give guidance on what rewards strategy should contain.

- Some important properties of RS in this framework are not stressed enough.

Well, let's take the above mentioned framework as a basis and complement it with other important ideas. We can sum up that RS should have the following properties: 
- be based on rewards strategy (for content of this strategy, see chapter "Rewards strategy"),

- be compliant:

- with laws in force,

- with the culture of the company (on the other hand it may be used as a tool for a change of this culture),

- with generally accepted ethical principles (Armstrong, 2010, p. 11-12):

- fairness - operating in accordance with the principles of distributive and procedural justice; by distributive justice is understood perceived fairness of decision outcomes relative to contributions and by procedural justice is understood perceived fairness of processes used to arrive at outcome decision,

- equity - rewarding people appropriately in relation to others within the organization; relativities between jobs should be measured as objectively as possible and equal pay should be provided for work of equal value,

- consistency - making decisions on pay consistently and not arbitrary between different people or at different time,

- be transparent - people should understand how rewarding processes work and how they are affected by them; issue of transparency includes quite unresearched problem whether salaries should be kept secret or not, see also (Case, 2001) and (Penttila, 2009),

- be competitive - externally to attract, motivate and retain employees,

- be unique - it is impossible to become the best and differentiate by only imitating others,

- reward contribution of individuals and teams; see also chapter "Impact of rewards on behaviour",

- give employees a choice to select between various types of rewards,

- maintain behaviour that is in compliance with company's needs throughout all levels of workforce (top management, middle management, line managers, other employees),

- be cost effective. 
To achieve the above mentioned desired properties (especially fairness, equity and consistency), RS has to incorporate the following fundamental elements:

- job descriptions as a result of job analysis and evaluation,

- base pay structures.

\section{Requirements on the updating procedures}

By "updating" is understood a continuous cycle of developing, implementing, using, evaluating and improving of RS. Desirable characteristics and content of these procedures can be divided into two categories - methodological ${ }^{1}$ and factual.

From the methodological point of view we prefer evidence based rewards management - a concept described into detail in (Armstrong Brown, 2010). Rousseau (2006, p. 256) proposed that "Evidence-based management(EBM) means translating principles based on best evidence into organizational practices. Through evidence-based management, practicing managers develop into experts who make organizational decisions informed by social science and organizational research." Evidence-based reward management (EBRM) is a specific application of EBM and according to Armstrong and Brown (2010, p. 34) can be defined as an "approach that uses the information obtained from internal and external surveys and the measurement and evaluation of reward practices to provide guidance on the development, implementation and operation of new or improved reward practices in accordance with defined reward goals and success criteria.".

From the factual viewpoint it is possible to conclude that implemented processes should first of all support fulfilling desired properties described in chapter "Commonly desired properties of RS". Armstrong and Brown (2010) advocate that the fundamental updating procedures are:

- setting reward strategy goals and defining success criteria,

- review of current reward policies and practices,

- measuring reward effectiveness,

- evaluating reward outcomes,

- development of the future reward practices,

- implementation of developed practices.

\footnotetext{
${ }^{1}$ By "methodology" we understand a specific approach used for updating of RS.
} 
These procedures are interlinked and do not necessarily follow in the above mentioned order.

We emphasize, that communication with all the involved (e.g. managers, employees, trade unions etc.) should be incorporated into all phases. WorldatWork (2007, p. 54) define communication as "creation of understanding and the transfer of meaning" and consider it to be a critical element in the success or failure of a total rewards program. Similarly Rubino (2008, p. 607) claims that "Effective communication of compensation programs is the most important component in the development and implementation of pay plans". Armstrong (2010, p. 438) points out that communication should not flow only top-down, but also in the opposite direction and emphasizes that employees should be aware of the value of their total reward package.

Content of setting reward strategy goals and defining success criteria was already described in the chapter "Rewards strategy". Here we add that reward strategy and goals are dynamic entities and should change according to the external environment as well as internal needs. Last but not least we point out that e.g. Lovewell $(2011$, p. 41) underlines that the first step in designing rewards strategy is always finding what employees actually want.

Reviewing of current reward policies and practices should include full understanding of current reward position and highlighting of the key reward issues. Both internal and external analysis is needed, including identification of main contextual factors, which have to be taken into account. Contextual factors according to (Armstrong, 2010, p. 16-19) include organization's culture (especially core values of the business), sector in which organization works, work environment (organization, type of management etc.), people (for segmenting rewards to better meet individual needs), business strategy, political and social climate within organization, impact of globalization, rates of pay in the market, economy, societal factors and legislation. In practice are according to (Gross - Friedman, 2004) the most often used information sources external benchmarking, best practices, employee surveys and internal statistical modelling.

There are many approaches for conducting review activity, some of which are explained in (Armstrong - Brown, 2010, p. 130-168). Internal research should firstly include analysis of existing reward policies and 
practices, e.g. whether activities like job evaluation, setting grade and pay structure and performance management including performance evaluation are executed correctly. Secondly, views of key groups of stakeholders (senior management, line managers and employees generally) should be examined, for example by surveys. External analysis should include legislation review (to ensure compliance), exploration of market pay levels and trends (for example by pay reviews), analysis of good practices (for example with the help of benchmarking, use of various surveys and relevant research). Armstrong and Brown (2010, p. 153) furthermore recommend to pay attention to the external research studies aimed at the effectiveness of reward practices and the conditions that have influence on this effectiveness. Internal and external information should be used for identifying of key issues and setting ways how to deal with them.

Measuring rewards effectiveness aims to collect, record, analyse and interpret data as a basis for evaluating the effectiveness of reward policy and practice and for informing reward development decisions (Armstrong - Brown, 2010, p. 170). Description of this process is beyond the scope of this paper and some examples of appropriate measures can be found e.g. in (Armstrong - Brown, 2010, p. 170-181) and in (WorldatWork, 2007, p. 47-50).

Evaluating means using information obtained from reward reviews and reward measurements to assess the level of effectiveness of the existing or new reward practices (Armstrong - Brown, 2010, p. 181). Armstrong gives the following methods of evaluating:

- comparison of existing practices with success criteria; examples of various evaluation criteria for assessing rewards goals can be found in (Armstrong - Brown, 2010, p. 183),

- using success criteria for evaluation of extent to which reward innovations have achieved their objective,

- ROI (Armstrong - Brown, 2010, p. 187),

- Return on expectations (Armstrong - Brown, 2010, p. 187-188),

- a four-level evaluation framework based on Kirkpatrick's model for training and development. We add that Kirkpatrick's model was created for evaluation of training programmes in 1959 and has been discussed in many articles, for example in (Kirkpatrick, 1979). This model was adjusted by for valuation of rewards effectiveness and described in (Scott - Morajda - McMullen, 2006) and (Scott - McMullen - Sperling, 2006). Scott advocates 
that ROI does not give enough information about RS effectiveness and that it is a lagging indicator. We consider Scott's model very well elaborated and probably the most comprehensive of all models mentioned here.

According to the results of evaluation, appropriate actions should be taken (development of the future reward practices). Finally, implementation of the developed reward practices should follow, which includes communication with employees and introducing of the new practices. Of course, process of continual improvement should be put in place.

\section{Alternative ways of influencing employee's behaviour}

We have already mentioned that RS should align the workforce with the business process and that it should be integrated vertically, horizontally and internally. Important fact is that there are also other tools for influencing employees than rewards. And indeed, in the newest articles and books on rewarding and motivating people, we can often see requests for a broader and multidisciplinary study of disposable tools for influencing employee's behaviour. For example (Manzoni, 2008) mentions research in the fields of economics, psychology and marketing/management.

Well, rewards are in these articles usually respected, but it is stressed that managers should use rewards very cautiously and combine them with other relevant tools. Manzoni (2010) points out that besides rewards there are numerous other levers, which are also of a great importance and should be used congruently with each other to support desired behaviour. Specifically Manzoni (2010, p. 53-55) names the following managerial levers for influencing individual behaviour:

- designing the jobs and the relationships between them in a way that enhances the intrinsic appeal of the job (this is also emphasized by Griffin (1981)),

- training managers to use supportive interpersonal style,

- recruiting people with a strong orientation toward autonomous motivation and a low desire for financial rewards (we add that more generally this rule should be formulated as hiring people that match the organization's needs),

- supporting prosocial behaviour from the top to the bottom of the organization. 
Other generally accepted means for enhancing motivation are:

- training employees,

- empowering,

- teamwork.

It is possible to conclude that monetary incentives are only one of the many tools for influencing the workforce behaviour. They cannot be taken neither as a substitute for good management (Osterloh - Frey, 2007, p. 444) nor as a substitute for a working environment high on trust, fun and meaningful work (Pfeffer, 1998, p. 118).

\section{Types of rewards, total rewards ${ }^{2}$}

In this chapter is give a brief summary of rewards types and an important concept of TR is introduced.

\section{Types of rewards}

Rewards can be classified according to:

- the form of reward:

- financial (tangible),

- non-financial (intangible),

- the time period for which is reward awarded:

- for the past performance,

- for the expected future performance,

- whom are rewards primarily allocated:

- individual rewards,

- team rewards,

- rewards for overall organization's performance,

- what is rewarded we distinguish rewards:

- for results,

- for the right behaviour,

- for skills,

- for meeting the job requirements, etc.

\footnotetext{
${ }^{2}$ Hereinafter the abbreviation "TR" is used for "total rewards".
} 
Well, variety of rewards is obviously tremendous and question "which of these rewards should be used?" can be arisen. The answer is that various rewards are appropriate for various purposes. Moreover selection of rewards depends on several contingent variables and further research is needed in this area. For example Zingheim and Schuster (2000, p. 28-31) underlines the importance of the business competitive position for selecting the right rewards strategy. Anyway, it is usually optimal to combine several types of rewards, ideally in a consolidated way.

\section{Total Rewards (TR)}

Armstrong (2010, p. 40) describes TR as an approach that integrates various types of rewards into a coherent whole.

There are many models of TR and a concise description of the wellknown ones (Towers Perrin, WorldatWork, Zingheim \& Schuster, IDS, Hay Group, Mercer, Sibson Consulting, Watson Wyatt) can be found in (Armstrong, 2010, p. 44-49). Most of these models contain not only identification of key elements of TR, but also suggestions for implementing TR.

The most comprehensively described TR model is probably the one from WorldatWork (2007) and it seems to us also very well elaborated and so we accept it as a basis for our further considerations.

\section{WorldatWork model}

WorldatWork (2007) framework offers not only a detailed classification of rewards but also procedures for deploying TR. Nevertheless description of these procedures is beyond the scope of this article and moreover we partially addressed this topic in chapter "Requirements on the updating procedures". Here we primarily want to outline the types of rewards recognized by WorldatWork:

- compensation (the largest component of rewards system and a major cost for organizations (WorldatWork, 2007, p. 90-91)):

- base pay (fixed pay; does not vary with achieved performance and results),

- salary, hourly or piece rates,

- knowledge or skill based pay, 
○ competency based pay,

- differentials (weekend/holiday, expatriate etc.),

○ pay increases (merit, lump-sum, step-rate, general, cost-ofliving, equity-based adjustments, market-based adjustments),

- variable pay (pay-at-risk, depends on achieved performance and results, must be re-established and re-earned each performance period); includes short-term incentive pay that is designed to focus and reward performance over a period of one year or less and long-term incentive pay that is designed to focus and reward performance over a period longer than one year (WorldatWork, 2007, p. 9):

$\circ$ organizational/team/individual,

○ profit-sharing plans,

$\circ$ performance-sharing (gain-sharing) plans,

- group/team incentives,

○ individual incentives (short-term incentive plans, salesincentive plans, executive incentive plans),

o discretionary bonuses (annual or spot),

- equity-based compensation (stock options, stocks grants, etc.),

- benefits (social insurance, group insurance, pay for time not worked (WorldatWork, 2007, p. 9) and also e.g. healthcare and other perks (Lovewell, 2011)),

- work-life balance (especially workplace flexibility, paid and unpaid time off, health and well-being, caring for dependents, financial support, community involvement, management involvement/culture change inventions (WorldatWork, 2007, p. 9); often mentioned are also telecommuting, flexitime, compressed workweek and paid family leave),

- performance and recognition (according to (WorldatWork, 2007, p. 10) RS should aim at alignment of organizational, team and individual efforts toward the achievement of business goals; recognition includes acknowledges and special attention to employee actions, efforts, behaviour or performance),

- development (learning programmes designed to enhance employees' skills and competencies) and career opportunities (includes plan for employees to advance in their career goals (WorldatWork, 2007, p. 8). 
Howsoever comprehensive WorldatWork model is, it is useful to complement it with ideas from other sources. Here we would like to underline the following facts:

- We miss more emphasis on creating a positive workplace - a component of total rewards stressed by Zingheim and Schuster (2000). By "positive workplace" is understood leadership, culture, atmosphere of trust and commitment, work content etc.

- Towers Perrin (from 2009 Towers Watson \& Co.) underlines that compensation and benefits can be easily copied by competitors while other types of rewards (intangible) are not easy to imitate and can create a long term competitive advantage.

- Rewards statements and other communication tools should be used so that employees think about the total rewards deal in integrated way (Gross - Bundy - Johnson, 2011).

- Classification of items under the category "compensation" is not fully clear. We prefer the classification given by Gagné and Forest (2008, p. 232) with some modifications (see Tab. 1). We emphasize that terminology is not unified and therefore other authors may define types of compensation differently.

Tab. 1: Common types of compensation

\begin{tabular}{|l|l|}
\hline \multicolumn{1}{|c|}{$\begin{array}{c}\text { Type of } \\
\text { compensation }\end{array}$} & \multicolumn{1}{c|}{ Characteristics } \\
\hline Base pay & $\begin{array}{l}\text { Paying a fixed amount of pay on a regular basis } \\
\text { (e.g. hourly, weekly, monthly) for occupying a } \\
\text { position in the company, regardless of } \\
\text { performance. Amount is typically determined by } \\
\text { job type, seniority or rank. }\end{array}$ \\
\hline Pay-for-performance & $\begin{array}{l}\text { Paying a set monetary reward for a pre-defined } \\
\text { performance unit. }\end{array}$ \\
\hline Bonus & $\begin{array}{l}\text { Paying a set monetary reward for attaining a } \\
\text { certain performance standard or quota. }\end{array}$ \\
\hline Merit pay & $\begin{array}{l}\text { Increasing base pay based on yearly performance } \\
\text { appraisal. }\end{array}$ \\
\hline Skill based pay & $\begin{array}{l}\text { Increasing base pay based on skill or knowledge } \\
\text { competencies and acquisition. }\end{array}$ \\
\hline
\end{tabular}




\begin{tabular}{|l|l|}
\hline \multicolumn{1}{|c|}{$\begin{array}{c}\text { Type of } \\
\text { compensation }\end{array}$} & \multicolumn{1}{c|}{ Characteristics } \\
\hline Gain sharing & $\begin{array}{l}\text { Giving a monetary reward based on reaching a } \\
\text { group based goal or quota. }\end{array}$ \\
\hline Profit sharing & $\begin{array}{l}\text { Sharing the organization's profit with its } \\
\text { employees. Pay out is based on a profitability } \\
\text { target. }\end{array}$ \\
\hline Stocks and options & $\begin{array}{l}\text { Giving stock ownership or the right to purchase a } \\
\text { fixed number of shares of stock at a fixed price. }\end{array}$ \\
\hline
\end{tabular}

Source: (Gagné - Forest, 2008, p. 232), own modifications

\section{Conclusions on total rewards}

It is possible to conclude that TR approach is broadly accepted both in theory and practice. For example Gross, Bundy and Johnson (2011, p. 11) mention a survey from 2010 realized in 741 multinational companies with the result that $73 \%$ of these companies reported using TR approach. Nevertheless there are significant differences in the degree of integration and Gross, Bundy and Johnson (2011, p. 15) suggested "total-rewards integration index" as a tool for its evaluation.

It is possible to conclude that there are many TR models of various levels of complexity. These models are largely complementary and it is possible to anticipate attempts for their integration into a more universal framework.

\section{Impact of rewards on behaviour}

It is broadly accepted that rewards have an impact on behaviour, nevertheless there are long-lasting disputes on whether rewards have positive or negative impact. These disputes originate in the field of psychology and proliferate into areas like human resources management, organizational theory and managerial accounting.

\section{Excursus to psychology - motivation}

Motivation can be defined in various ways. Rai (2004, p. 43) gives the following definition of motivation: "the willingness to exert a high level of effort towards organisational goals, conditioned by the employee's 
ability to satisfy some individual need". It is broadly accepted that the motivated employees are usually outperforming the not-motivated ones and the question therefore is how to motivate people. There are numerous theories of motivation. For example Gagné and Deci (2005, p. 340-345) name and concisely evaluate goal-setting theory (Locke \& Latham), action regulation theory (Frese \& Sabini, Hacker), Kanfer's task-specific motivation, job characteristics theory (Hackman and Oldham; emphasizes importance of job-design for motivation), needs and motives theory (Maslow, Herzberg, Alderfer), Kelman's theory of internalization and the concept of identification (Kelman), organizational commitment (Chatman \& Kelman; Allen \& Meyer).

Despite the fact all above mentioned theories are very inspiring, in connection with rewards we find especially relevant model of intrinsic and extrinsic work motivation proposed in (Porter - Lawler, 1968) and substantially changed and developed by Deci and his colleagues.

According to Deci (1975) there are 2 types of motivation:

- extrinsic motivation which requires an instrumentality between the activity and some separable consequence; satisfaction comes not from the activity itself but rather from the extrinsic rewards obtained for performing the activity in the required way,

- intrinsic motivation which is demonstrated when people engage in an activity for its own sake and not because of any extrinsic reward.

Originally it was supposed that extrinsic and intrinsic motivation were additive. Nevertheless number of empirical studies conducted especially by Deci and his colleagues proposed that dependence between intrinsic and extrinsic motivation is rather both positively and negatively interactive instead of additive.

These findings were not accepted by all researchers. For example Cameron and Pierce (1994) concluded that rewards do not decrease intrinsic motivation. Verbal praise even leads to increase in intrinsic motivation. The only (minimal) negative effect on intrinsic motivation appears when expected tangible rewards are given to individuals just for doing a task. Well, Cameron's findings were repeatedly questioned, for example in (Deci - Koestner - Ryan, 1999). 
As the first attempt to explain effects of extrinsic motivators on intrinsic motivation, cognitive evaluation theory (hereinafter "CET") was created by Deci and lately developed also by other researchers. Gagné and Deci (2005, p. 332-333) highlight the following findings:

- negative feedback undermines both extrinsic and intrinsic motivation,

- some external factors (e.g. providing choice about task engagement, verbal rewards, positive feedback) tend to increase intrinsic motivation; assumption was made that factors that promote feelings of autonomy and competence enhance intrinsic motivation,

- external factors like tangible rewards, deadlines, surveillance tend to diminish feelings of autonomy and undermine intrinsic motivation; nevertheless according to research studies the intrinsic motivation was not undermined when:

- rewards were given independent of specific task engagement or when the rewards were not anticipated tangible extrinsic rewards did not undermine intrinsic motivation,

- rewards were contingent on high-quality performance and interpersonal context was supportive - in this case tangible rewards increased intrinsic motivation,

- contingent tangible rewards, competition and evaluation (measurement) may decrease creativity, cognitive flexibility and ability for problem-solving.

Though CET brought some important insights (i.e. distinction of extrinsic and intrinsic motivation, pointing out that some rewards, e.g. fixed salary and unexpected bonuses, do not decrease intrinsic motivation), it was not easy to make use of it in organizational environment.

Consequently (around 1985), self-determination theory (hereinafter "SDT") was proposed by Deci, Ryan and Connell. SDT distinguishes:

- amotivation (not having intention to act),

- autonomous motivation (connected with sense of volition and having the experience of choice in acting; includes both intrinsic motivation, which is fully autonomous and internalized and well internalized extrinsic motivation),

- controlled motivation. 
It is beyond the scope of this paper to analyse fundamental determinants of work motivation from a psychological point of view. Nevertheless we want to highlight the following propositions of SDT that we find especially important from the viewpoint of impacts of compensation on work motivation and performance:

- there are individual differences in people's causality orientation toward the initiation and regulation of their behaviour (which can be autonomy oriented, control oriented and impersonally oriented),

- autonomous motivation is especially important for increasing performance on tasks that are either interesting or personally important tasks; increased performance is usually connected with individual well-being and satisfaction (Gagné - Deci, 2005, p. 352); for mundane tasks autonomous motivation does not have significant impact on performance (Gagné - Deci, 2005, p. 347),

- autonomous motivation increases well-being and satisfaction even in case of mundane jobs (Gagné - Deci, 2005, p. 347),

- controlled motivation can be even or more effective than autonomous motivation for increasing performance on tasks that are usually considered to be uninteresting and carried primarily for money; in this case increased performance can be associated with lowering of personal satisfaction (Gagné Deci, 2005, p. 352),

- autonomous motivation can be effectively promoted by job enlargement (both horizontal and vertical) and by support of relatedness, e.g. by creating interdependence among employees (Gagné - Deci, 2005, p. 354),

- fixed pay should not substantially undermine intrinsic motivation as it is a type of reward "given independent of specific task engagement", variable pay is much more dangerous in this sense,

- higher base pay level suggests recognition of high competence and fosters better performance (Gagné - Forest, 2008, p. 228),

- impact of ratio of variable versus fixed pay on motivation is ambiguous and requires further research (Gagné - Forest, 2008, p. 228),

- in autonomy-supportive climate (free from competition among team-mates or pressure to meet the numbers) performancecontingent rewards are less likely to decrease intrinsic motivation; 
in this case rewards can even increase intrinsic motivation (Gagné - Deci, 2005, p. 354),

- rewards must be perceived as equitable in order not to have negative effects (Gagné - Deci, 2005, p. 354),

- feeling of procedural justice is influenced by:

- determinants of compensation (e.g. individual characteristics or individual performance),

- methods of evaluation; these may be more formula-based or based on an expert's judgment (possibly based on managerial decision); criteria and their desired values may be set in advance or later in the process of evaluation.

Well, it is possible to sum up that in an organizational content the question "Rewards - yes or not?" is not relevant as employees need to get monetary rewards for their living. Question should be transformed to "Which forms (types) of rewards should be preferred under specific circumstances?" and "Which should be relative proportions and properties of these rewards?".

\section{Views on incentives ${ }^{3}$ throughout organizational, human resources and managerial accounting literature}

\section{Highly negative attitudes towards incentives}

Let's start with some of the most influential opinions that are refusing incentives or at least stressing their disadvantages.

Ideas against incentives were strongly and consistently expressed in the article "Why Incentive Plans Cannot Work" (Kohn, 1993). Kohn is in his writings sceptical about behaviourist theory and advocates that "failure of any given incentive program is due less to a glitch in that program than to the inadequacy of the psychological assumptions that ground all such plans" (Kohn, 1993, p. 54). According to Kohn's opinions, incentives are good only for acquiring temporal compliance, not for altering attitudes. Kohn does not believe that incentive system can be repaired by improving its implementation and is distrustful about positive impact of compensation in general and especially about pay-forperformance, which he considers to be harmful. As a solution Kohn:

3 Hereinafter by "incentives" are understand contingent monetary rewards for performance. 
- suggests to "pay people well and... then do everything possible to help them forget about money",

- stresses the importance of intrinsic motivation.

Similar opinions as Kohn's ones are mentioned in the article "Six Dangerous Myths about Pay" by Pfeffer (1998) (with some important differences, nevertheless similarities are also obvious). According to Pfeffer (1998) companies often believe in six dangerous myths which lead them to accepting wrong rewarding systems. These myths include conviction that individual incentive pay improves performance and belief that people work (only) for money. Pfeffer heavily criticizes individual incentives and suggests to use reward schemes that emphasize team work and not individual performance. As for last "myth" Pfeffer suggests companies to use all means to emphasize other factors that make them attractive for employees.

Frey and Osterloh (2005) analyse the impact of pay for performance on behaviour of managers and directors and concludes that pay for performance increases the extrinsic motivation nevertheless crowds out the intrinsic motivation and the net effect on behaviour tends to be negative.

\section{Highly positive attitudes towards incentives}

Despite the above listed disadvantages and risks of using incentives, there is a large group of academics, consultants and practitioners who believe that incentives are very useful and of utmost importance for motivating employees. Various surveys show both high degree of acceptance of pay-for-performance programmes and rising proportion of jobs covered by pay-for-performance in practice. Proponents of incentives often base their approaches on the agency theory and usually refuse negative impact of incentives on intrinsic motivation or do not mention it at all.

Proponents of incentives are aware that there are dangers in using monetary rewards for awarding performance, nevertheless they believe that incentives fail only for incidental reasons (misuse of rewards, unintentional or intentional rewarding for wrong behaviour etc.) and therefore are avoidable. 
Kerr in his article "On the folly of rewarding A while hoping for B" (1975) pointed out and illustrated on many examples, that firms often reward behaviour A although they hope for behaviour B and as solution suggested that firms should analyse their reward system, try to recognize whether they reward wrong behaviour and if so then alter the system. According to him it usually means choosing different measures or more complex measures.

Among radical supporters of incentives belong proponents of economic value added, see e.g. (Stewart, 1991). Similarly proponents of shareholder value added also support incentives (Rappaport, 1998).

\section{Contemporary views on incentives - moderate attitudes}

It seems that contemporary views are less radical and much more pragmatic. Influence of theories like CET and SDT is growing though agency theory still has an important role. Researchers often use interdisciplinary approach, refuse universal theories and stress that usefulness of incentives depends on contextual factors.

For example Manzoni (2008, 2010) criticizes narrow views on incentives, underlines that imperative "let's get incentives right" should not be the only response to problems with motivating employees and suggests to use more "levers" than incentives and an interdisciplinary approach to work motivation. Call for interdisciplinary research is answered e.g. in (Osterloh - Frey, 2007), where SDT is largely addressed together with theories from other disciplines.

Last but not least warnings about self-fulfilling nature of some theories can be found. For example if we believe people are untrustworthy and control them more closely, they will be tempted to cheat (Pfeffer, 1998) and similarly (Manzoni, 2008, p. 19, 36-38) and (Austin - Gittell, 2007, p. 472).

\section{Framework for analysis of using incentives}

We suppose to address the issue of incentives in more detail in another article prepared within our research project. Here we only briefly introduce a framework that can be used for an analysis of using incentives. The framework is partially motivated by a scheme proposed in (Beel, 2007), nevertheless adjusted for analysis of incentives, 
substantially extended and supplemented with ideas from other sources and our own experience. It can be used both as an aid for evaluation/design incentives systems in practice and as a tool for analysing theoretical performance management and measurement frameworks from the viewpoint of their approach to incentives.

1. Are / should be incentives used?

2. What procedures are / should be put in place and what levers should be employed to support positive effect of incentives on motivation and performance?

3. Who is / should be included in incentives programme and on which criteria is / should be selection based?; e.g.:

- individual/team/company-wide incentives,

- according to job characteristics (highly routinized jobs vs. creative ones),

- according to professions (sales staff, manual workers, executives, ...),

- according to hierarchical position (corporate level executives, business-level unit managers, line managers, other employees).

4. Are / should be incentives based on one performance measure (e.g. EVA, SVA) or on a set of measures?

5. Which measures are / should be used for evaluation of performance and how to set reference values? Is appropriateness of selected measures constantly reviewed and compared with objectives that a company wants to accomplish? It is possible to find numerous advices for selecting proper measures throughout literature dedicated to rewarding and/or performance measurement, for example in (Armstrong, 2010, p. 167-211), (Brown, 2008), (Neely - Adams - Kennerley, 2002), (Wagner Šoljaková-Matyáš, 2007), (Young - O'Byrne, 2000). Nevertheless analysis of these advices is beyond the scope of this paper. We only want to warn about understanding these rules dogmatically as universally valid truths.

6. To which degree is / should be the calculation of incentives algorithmic (formula-based) and to which degree it is based on subjective judgment?

7. What is / should be the relative importance of incentives compared to the other components of compensation? Are incentives tapped or not? 
8. How often (frequency) are / should be incentives calculated and paid out to employees?

9. Is /should be paid whole reward or is partially retained and paid out later?

10. Does / should incentives system reward both short-term and longterm objectives?

\section{Conclusion}

The paper outlined the fundamental requirements (properties and procedures) that should RS meet to be effective in supporting overall company's strategy. Furthermore, the issue of employee's motivation was addressed and considered in connection with rewards generally as well as specifically in connection with monetary rewards for performance. It was stressed that rewards are only one of the many tools for influencing motivation and behavior of a company's workforce and that all these tools should be used in mutual congruence. Last but not least a framework which can be used both in practice (for structured analysis of incentive programme in use) and for evaluating of theoretical frameworks from the viewpoint of their approach to incentives was proposed. Further development of this framework is planned.

It is also supposed that this paper will serve us as a theoretical basis and depository of ideas for designing questions which will be consequently included in a questionnaire for the first phase of our empirical research into the quality of rewards systems implemented in Czech companies.

\section{References}

[1] Armstrong, M. (2010): Armstrong's Handbook of Reward Management Practice: Improving Performance through Reward. London, Kogan Page, 2010.

[2] Armstrong, M. - Brown, D. (2010): Evidence-Based Reward Management: Creating Measurable Business Impact from Your Pay and Reward Practices. London, Kogan Page, 2010.

[3] Austin, R. - Gittell, J. H. (2007): Anomalities of Measurement: When It Works, but Should Not. In: Neely, A. D. (ed.): Business Performance Measurement: Unifying Theories and Integrating Practice. Cambridge, Cambridge University Press, 2007, pp. 449-476. 
Petera, P.: Evaluating the Quality of Rewards Systems.

[4] Beel, J. (2007): Project Team Rewards: Rewarding and Motivating your Project Team. Scotts Valley, CreateSpace, 2007.

[5] Brown, M. G. (2008): Performance Metrics and Compensation. In Berger, L. A. - Berger, D. R. (eds.): The Compensation Handbook: A State-of-the-Art Guide to Compensation Strategy and Design. New York, McGraw-Hill, 2008, pp. 511-520.

[6] Cameron, J. - Pierce, W. D. (1994): Reinforcement, Reward, and Intrinsic Motivation: A Meta-Analysis. Review of Educational Research, 1994, vol. 64, no. 3, pp. 363-423.

[7] Case, J. (2001): When Salaries Aren't Secret. Harvard Business Review, 2001, vol. 79, no. 5, pp.37-44.

[8] Deci, E. (1975): Intrinsic Motivation. New York, Plenum Press, 1975.

[9] Deci, E. - Koestner, R. - Ryan, R. (1999): A Meta-Analytic Review of Experiments Examining the Effects of Extrinsic Rewards on Intrinsic Motivation. Psychological Bulletin. 1999, vol. 125, no. 6, pp. 627-668.

[10] Frey, B. - Osterloh, M. (2005): Yes, Managers Should Be Paid Like Bureaucrats. Journal of Management Inquiry, 2005, vol. 14, no. 1, pp. 96-111.

[11] Gagné, M. - Deci, E. (2005): Self-Determination Theory and Work Motivation. Journal of Organizational Behavior, 2005, vol. 26, no. 4, pp. 331-362.

[12] Gagné, M. - Forest, J. (2008): The Study of Compensation Systems through the Lens of Self-Determination Theory: Reconciling 35 Years of Debate. Canadian Psychology, 2008, vol. 49, no. 3, pp. 225232.

[13] Griffin, R. - Welsh, A. - Moorhead, G. (1981): Perceived Task Characteristics and Employee Performance: A Literature Review. The Academy of Management Review, 1981, vol. 6, no. 4, pp. 655664.

[14] Gross, S. - Friedman, H. (2004): Creating an Effective Total Reward Strategy: Holistic Approach Better Supports Business Success. Benefits Quarterly, 2004, vol. 20, no. 3, pp. 7-12.

[15] Gross, S. - Bundy, K. - Johnson, R. (2011): The Ongoing Integration of Total Rewards. Employment Relations Today, 2011, vol. 37, no. 4, pp. 11-17. 
[16] Kerr, S. (1975): On The Folly of Rewarding A, while Hoping for B. Academy of Management Journal, 1975, vol. 18, no. 4, pp. 769-783.

[17] Kirkpatrick, D. L. (1979): Techniques for Evaluating Training Programs. Training \& Development Journal. 1979, vol. 33, no. 6, pp. 78-92.

[18] Kohn, A. (1993): Why Incentive Plans Cannot Work. Harvard Business Review, 1993, vol. 71, no. 5, pp. 54-63.

[19] Lovewell, D. (2011): A Totally Rewarding Strategy. Corporate Adviser, 2011, vol. 3, no. 3, pp. 39-42.

[20] Manzoni, J. F. (2008): On The Folly of Hoping for A Simply because You Are Trying to Pay for A. In: Epstein, M. J. - Manzoni, J. F. (eds.): Performance Measurement and Management Control: Measuring and Rewarding Performance. Bingley, Emerald JAI, 2008, pp. 19-41.

[21] Manzoni, J. F. (2010): Motivation through Incentives: A CrossDisciplinary Review of the Evidence. In: Epstein, M. C. - Manzoni, J. F. - Davila, A. (eds.): Performance Measurement and Management Control: Measuring and Rewarding Performance. Bingley, Emerald, 2010, pp. 19-63.

[22] Neely, A. D. - Adams, C. - Kennerley, M. (2002): The Performance Prism: The Scorecard for Measuring and Managing Business Success. London, Financial Times Prentice Hall, 2002.

[23] Osterloh, M. - Frey, B. (2007): Does Pay for Performance Really Motivate Employees? In: Neely, A. D. (ed.): Business Performance Measurement: Unifying Theories and Integrating Practice. Cambridge, Cambridge University Press, 2007, pp. 433-448.

[24] Penttila, C. (2009): The Salary Secret is Out. Entrepreneur. 2009, vol. 37 , no. 1 , pp. 23.

[25] Pfeffer, J. (1998): Six Dangerous Myths about Pay. Harvard Business Review, 1998, vol. 76, no. 3, pp. 109-119.

[26] Porter, L. W. - Lawler, E. E. (1968): Managerial Attitudes and Performance. Homewood, Irwin, 1968.

[27] Rai, S. (2004): Motivational Theories and Incentives Approaches. Indian Institute of Management Bangalore Management Review, 2004, vol. 16, no. 4, pp. 43-50. 
Petera, P.: Evaluating the Quality of Rewards Systems.

[28] Rappaport, A. (1998): Creating Shareholder Value: A Guide for Managers and Investors. New York, Free Press, 1998.

[29] Rousseau, D. (2006): Is There Such a Thing as "Evidence-Based Management"? Academy of Management Review, 2006, vol. 31, no. 2, pp. 256-269.

[30] Rubino, J. (2008): Communicating Compensation Programs. In: Berger, L. A. - Berger, D. R. (eds.): The Compensation Handbook: A State-of-The-Art Guide to Compensation Strategy and Design. New York, McGraw-Hill, 2008, pp. 607-615.

[31] Scott, D. - Morajda, D. - McMullen, T. D. (2006): Evaluating Pay Program Effectiveness. WorldatWork Journal, 2006, vol. 15, no. 2, pp. 50-59.

[32] Scott, D. - McMullen, T. D. - Sperling, R. S. (2006): Evaluating Pay Program Effectiveness: A National Survey of Compensation Professionals. WorldatWork Journal, 2006, vol. 15, no. 3, pp. 47-53.

[33] Stewart, G. B. (1991): The Quest for Value: the EVA ${ }^{T M}$ Management Guide. New York, HarperCollins, 1991.

[34] Wagner, J. - Šoljaková, L. - Matyáš, O. (2007): Strategic Performance Measurement and Compensation Systems in the Czech Republic (Empirical study). European Financial and Accounting Journal, 2007, vol. 2, no. 3-4, pp. 8-26.

[35] WorldatWork (Organization) (2007): The Worldatwork Handbook of Compensation, Benefits \& Total Rewards: A Comprehensive Guide for HR Professionals. New York, Wiley, 2007.

[36] Young, S. D. - O'Byrne, S. F. (2000): EVA and Value-Based Management: A Practical Guide to Implementation. New York, McGraw-Hill, 2000.

[37]Zingheim, P. K. - Schuster, J. R. (2000): Pay People Right! Breakthrough Reward Strategies to Create Great Companies. San Francisco, Jossey-Bass, 2000. 


\title{
Evaluating the Quality of Rewards Systems
}

\author{
Petr PETERA
}

\begin{abstract}
This paper deals with the issue of desired characteristics of rewards systems and outlines possible ways of their evaluation. Aims of the rewards systems are analyzed and desired properties, components and updating procedures that should be put in place are identified. Rewards system is understood as a tool for supporting business's goals, attracting, motivating and retaining competent employees. It is stressed that rewards system is an important but not the only tool for reaching the mentioned goals and it should be used congruently with other tools (e.g. proper job design, recruiting, training, creating positive workplace). An encyclopedic preview of rewards types is given, their various classifications are introduced and it is underlined that type of chosen reward should match with the objective that is supposed to be accomplished. Finally, the impact of rewards on motivation and behavior is addressed and a framework for analyzing of incentives (variable payments for performance) is proposed.
\end{abstract}

Key words: Rewards; Performance; Motivation.

JEL classification: M52. 